\title{
Crystal engineering of metal-organic frameworks
}

\section{containing amide functionalities: Studies on network}

recognitions, transformations and exchange dynamics of

\author{
guests and anions
}

\author{
Madhushree Sarkar and Kumar Biradha* \\ Department of Chemistry, Indian Institute of Technology, Kharagpur-721302, India \\ Fax:+91-3222-282252; Tel: +91-3222-283346; \\ E-mail: kbiradha@chem.iitkgp.ernet.in
}

Supporting Information

IR Spectra of complexes 3-13;

guest exchange reactions of $\mathbf{6}$;

anion exchange reactions of $\mathbf{8 , 9}$ and $\mathbf{1 3}$

TGA of complexes 4, 6, 7 and $\mathbf{9}$

Powder XRD for guest exchange reactions of $\mathbf{6}$ 
IR Spectra of complex 3:

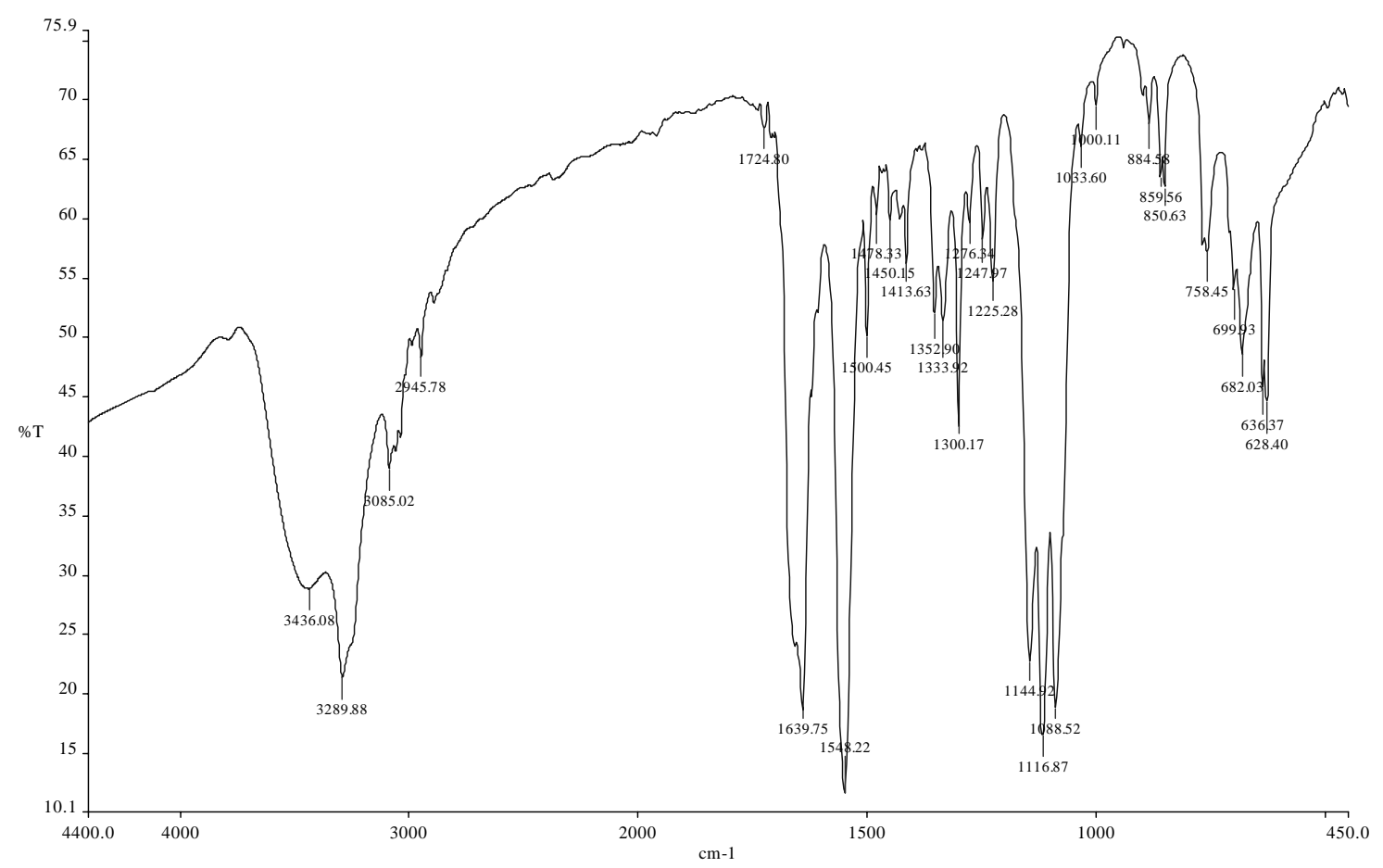

IR Spectrum of 4a:

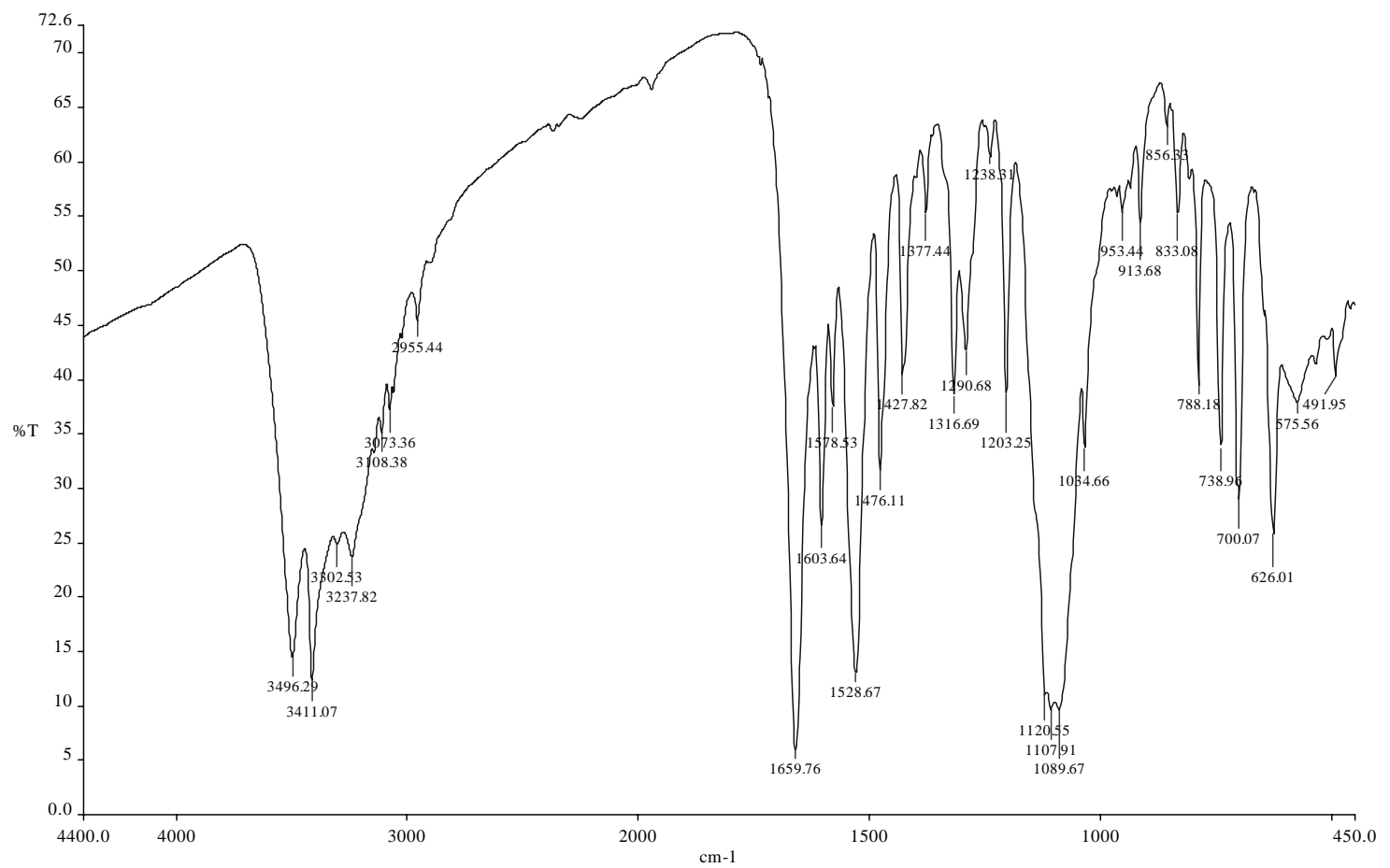


IR Spectrum of $\mathbf{4 b}$ :

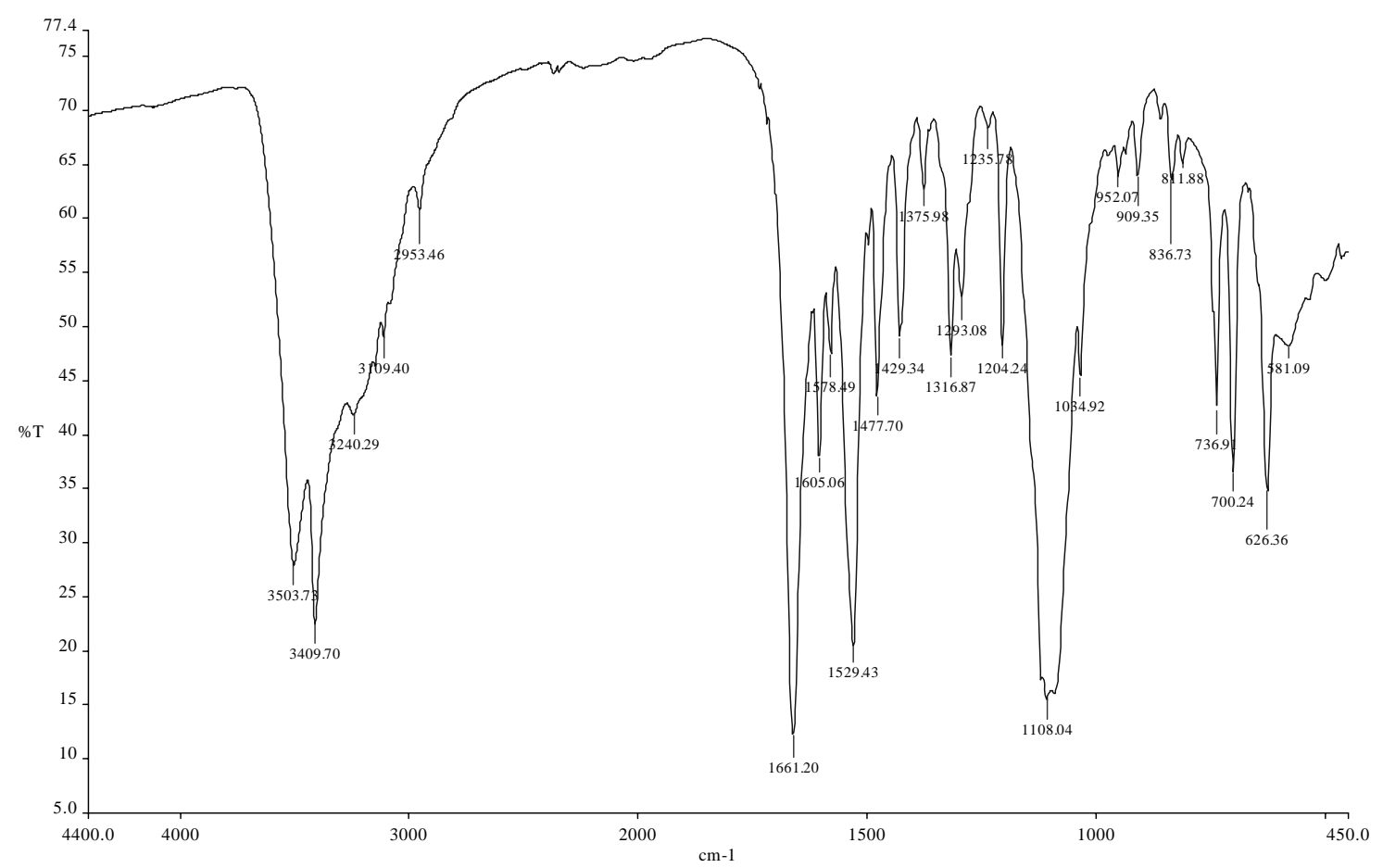

IR Spectrum of 4c:

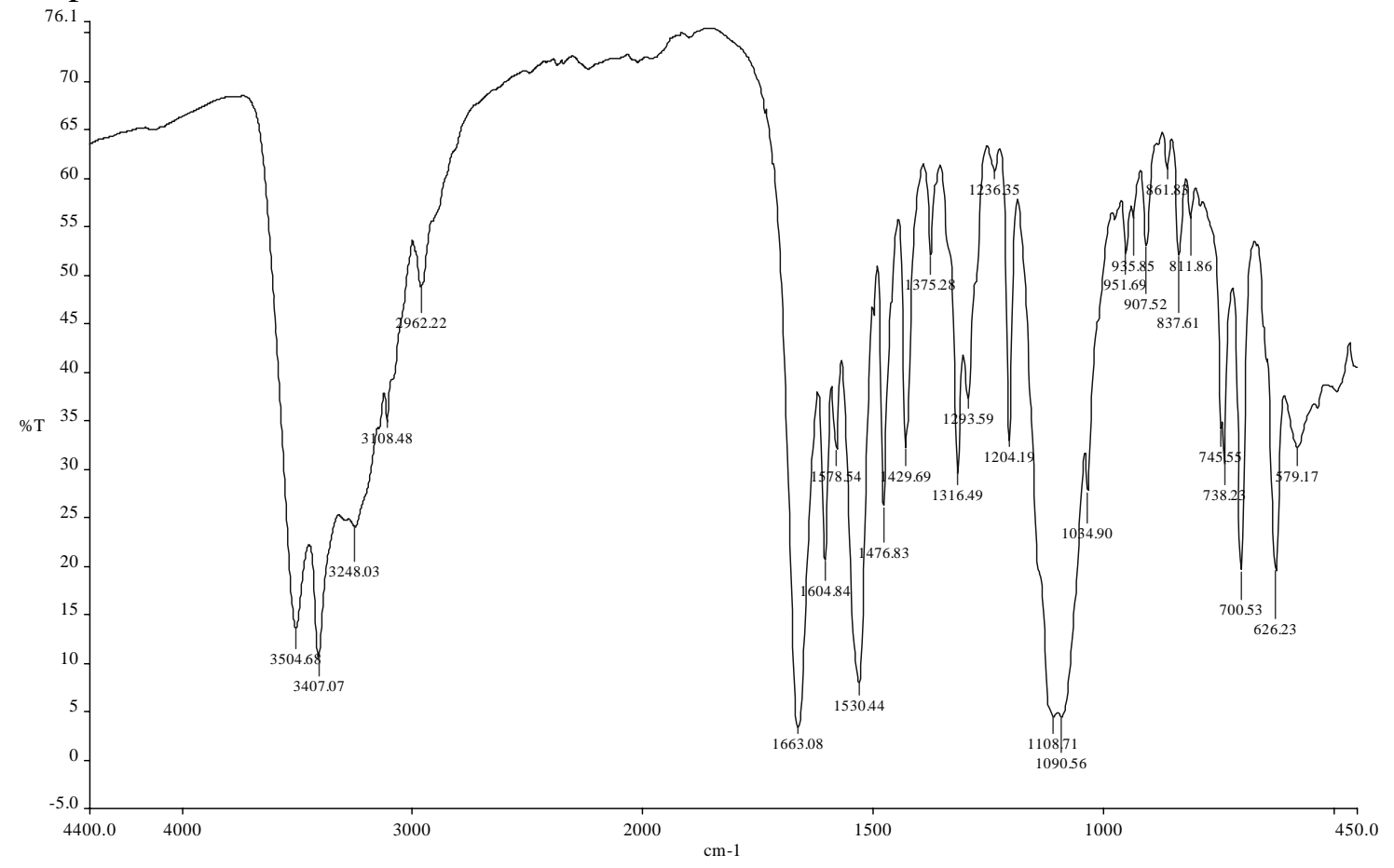


IR Spectrum of $\mathbf{4 d}$ :

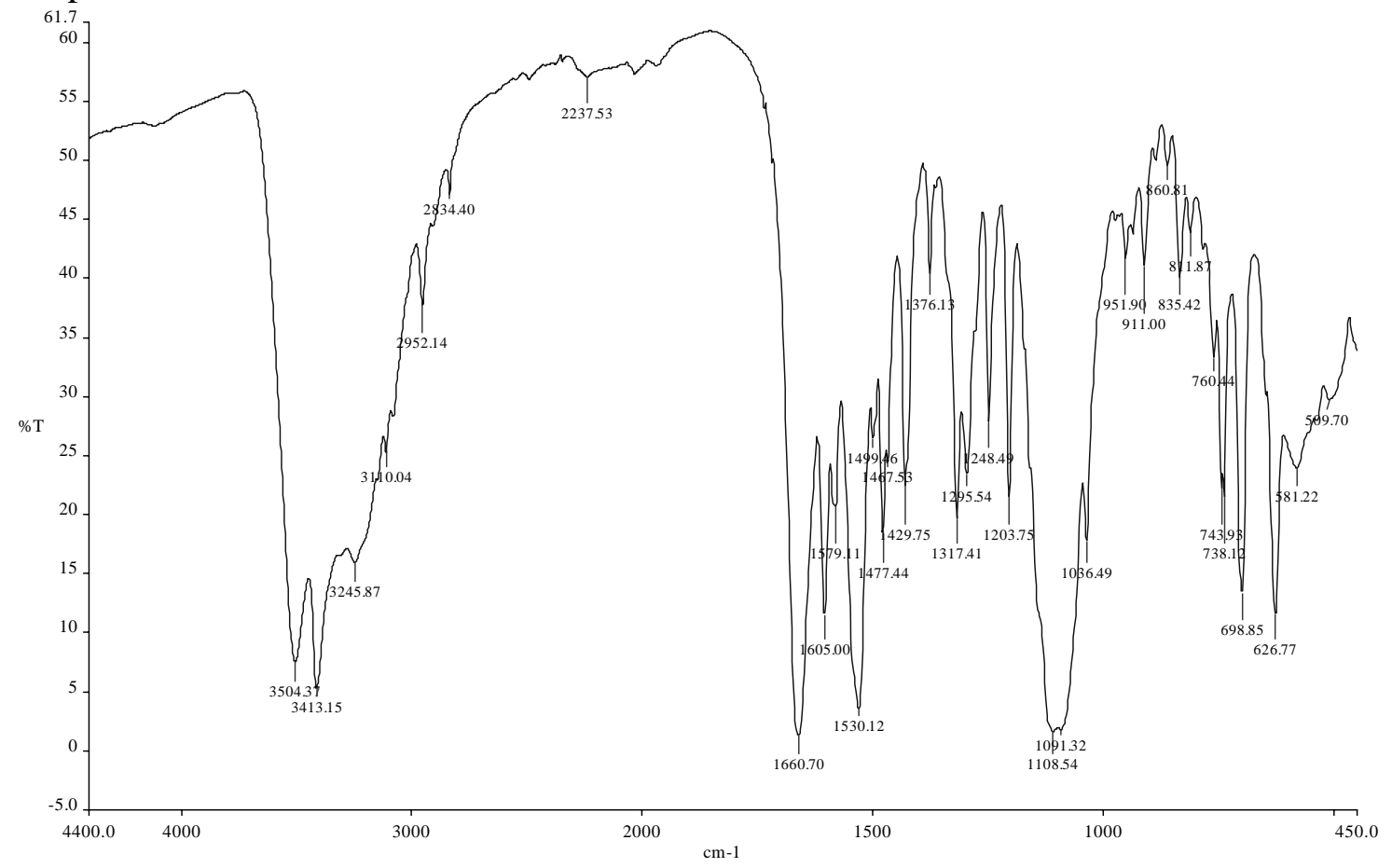

IR Spectrum of 5:

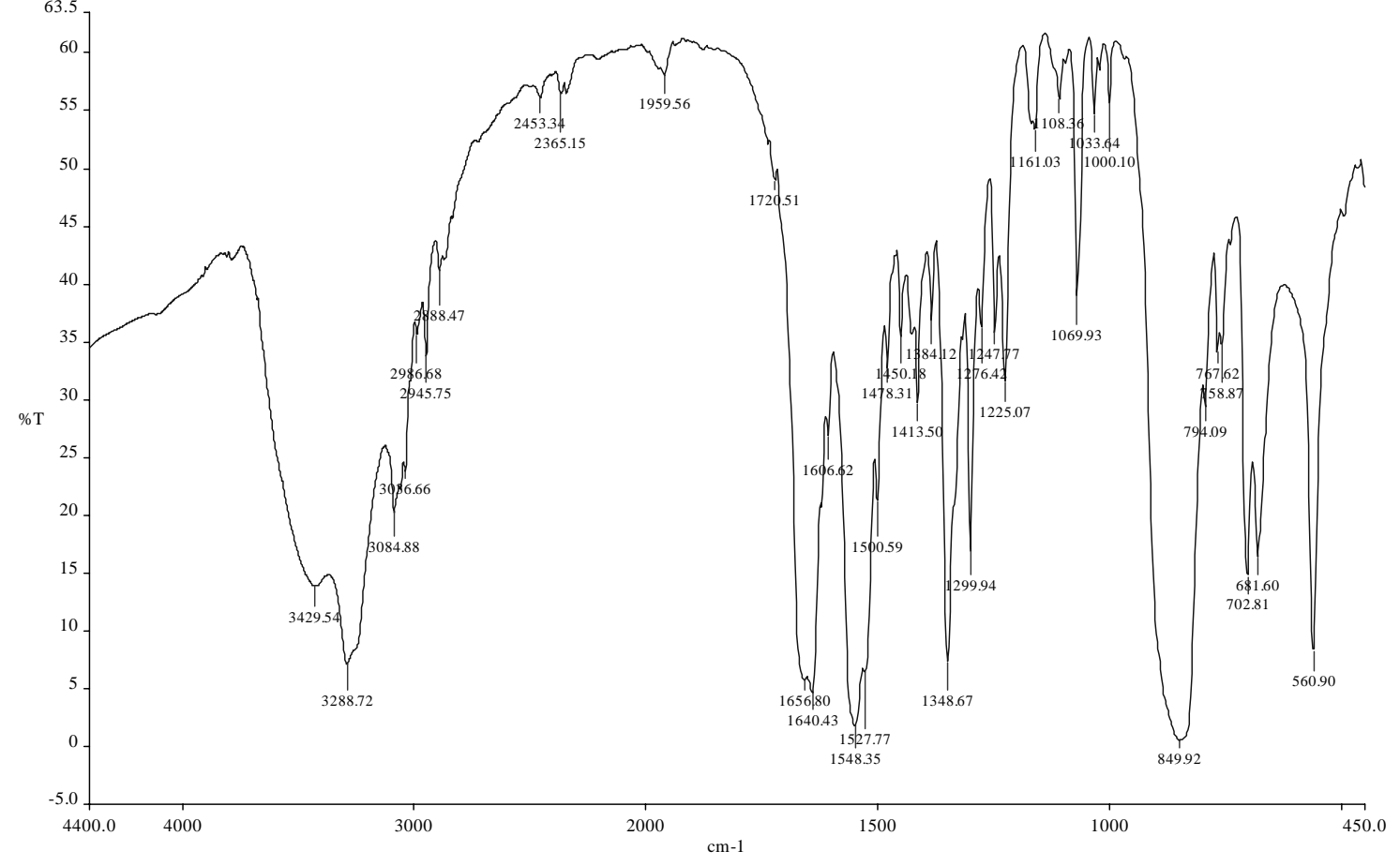


IR Spectrum of $\mathbf{6}$ :
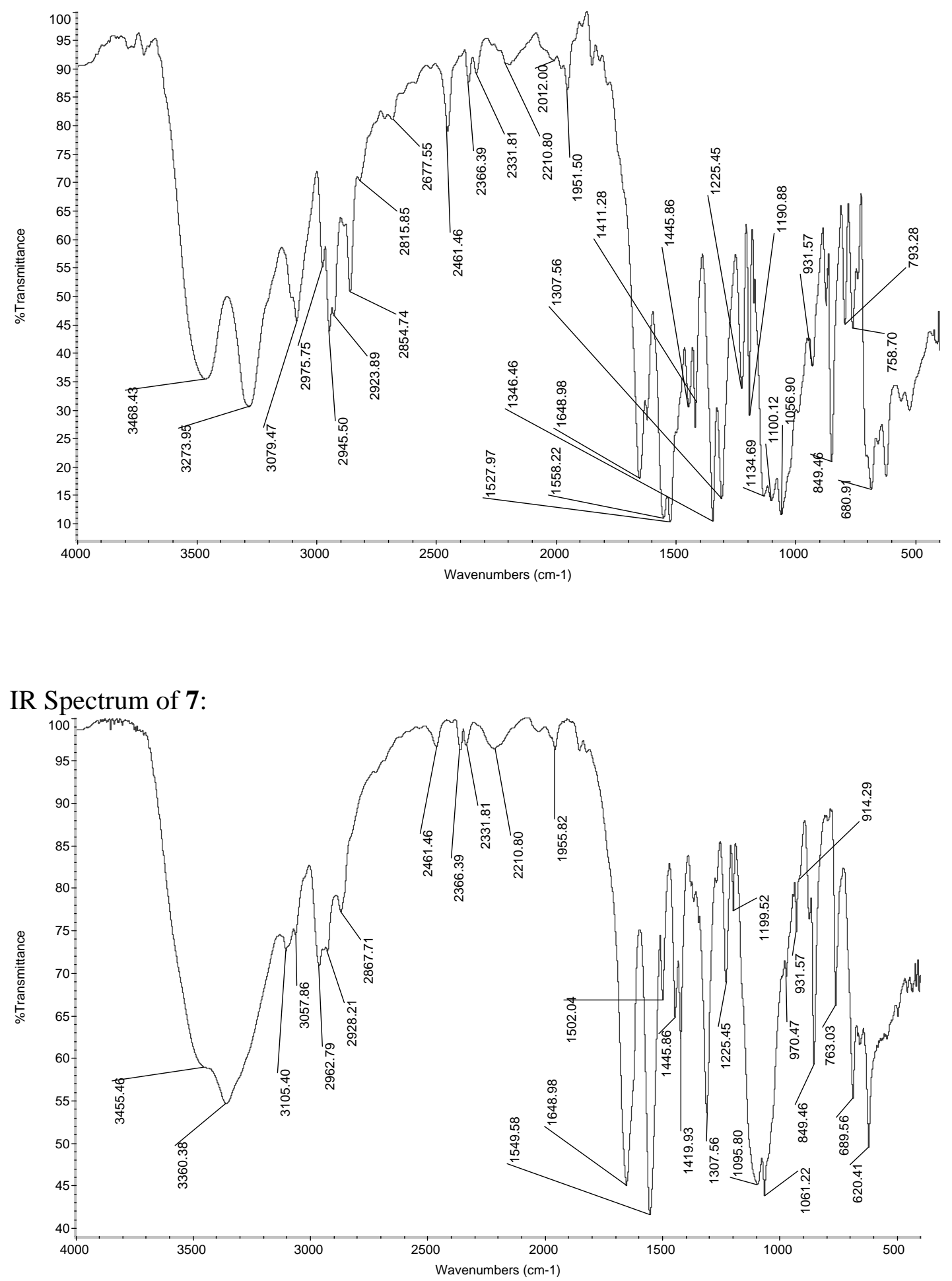
IR Spectrum of $\mathbf{8}$ :

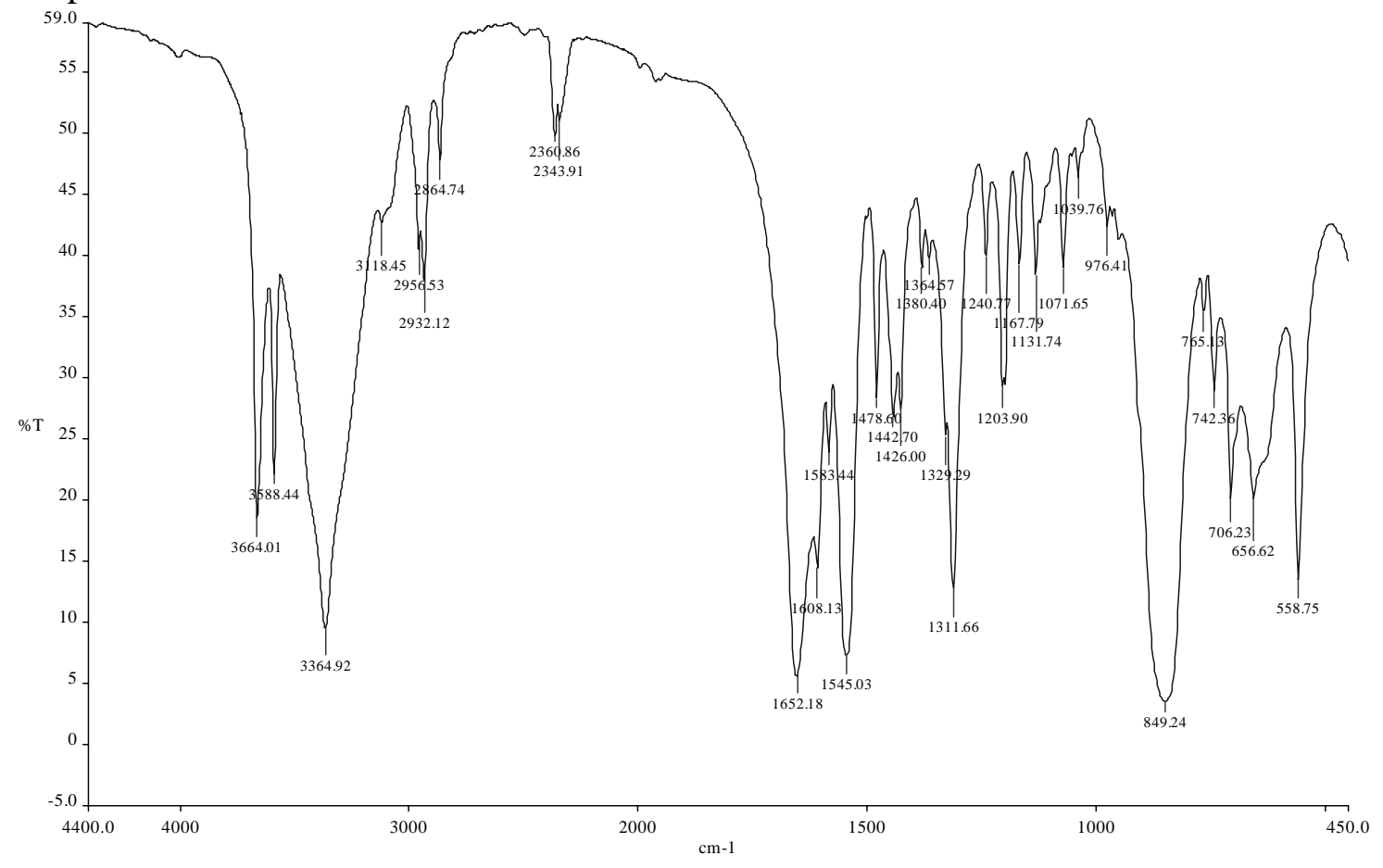

IR Spectrum of $\mathbf{9}$ :

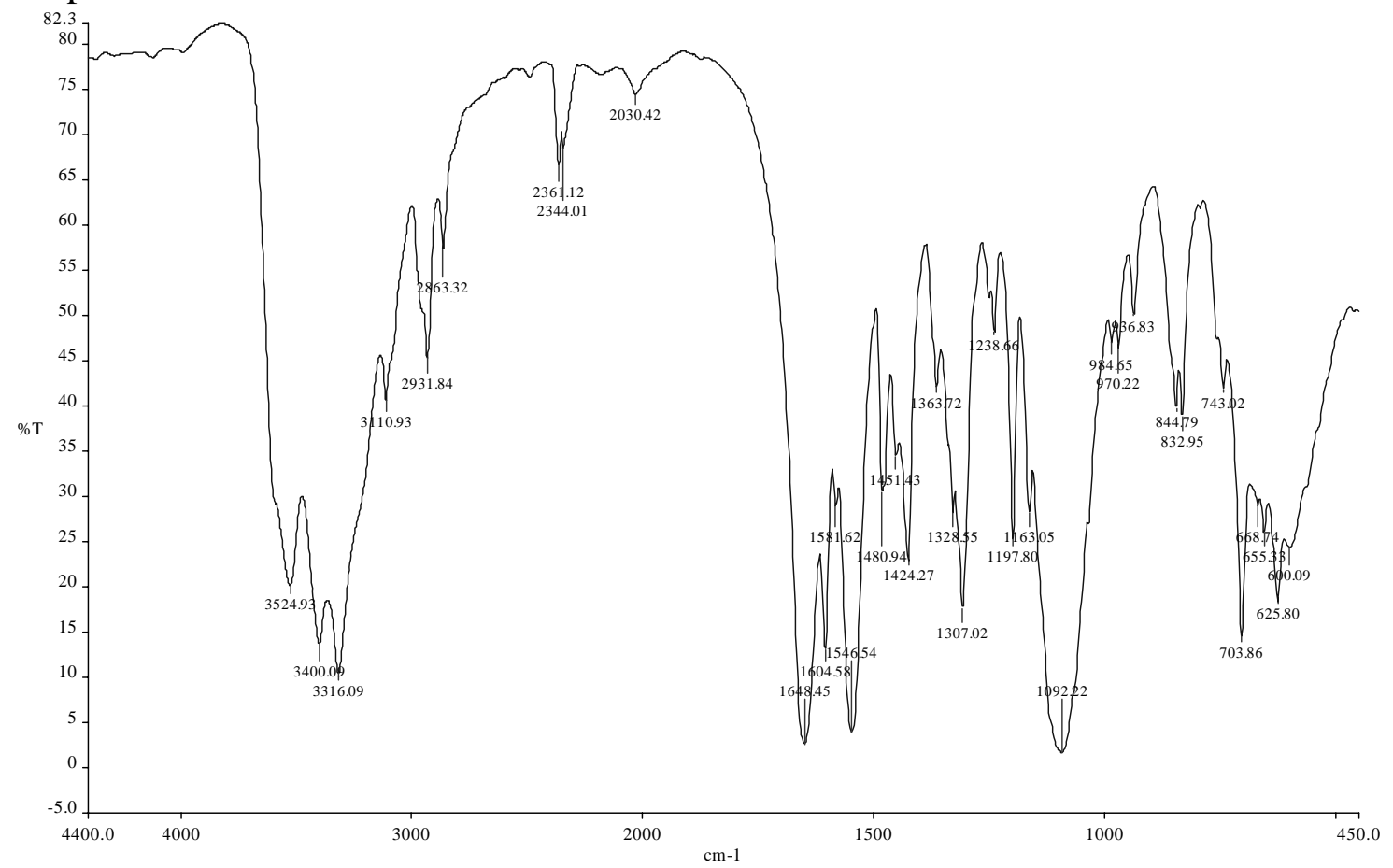


IR Spectrum of 10:

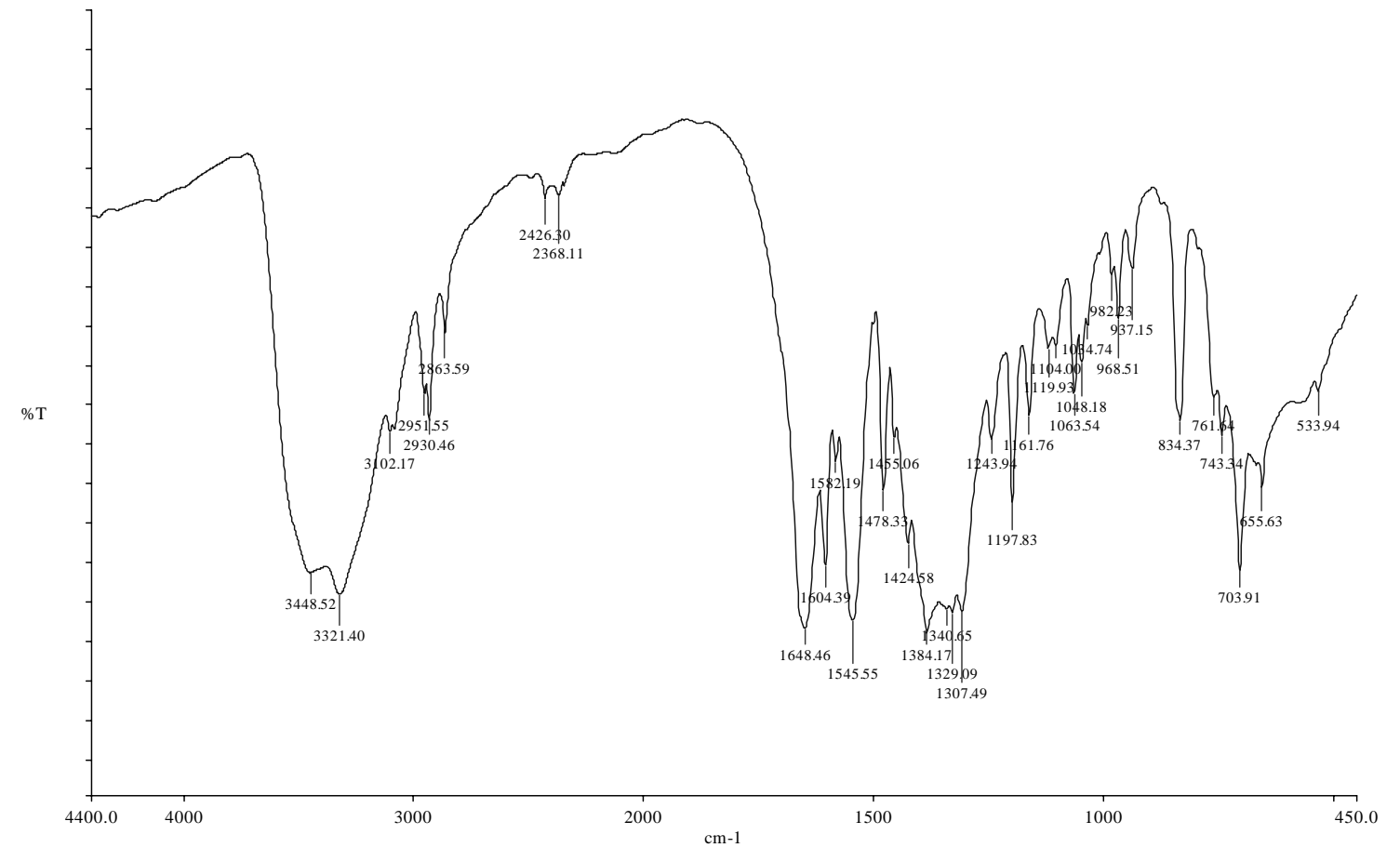

IR Spectrum of 11:

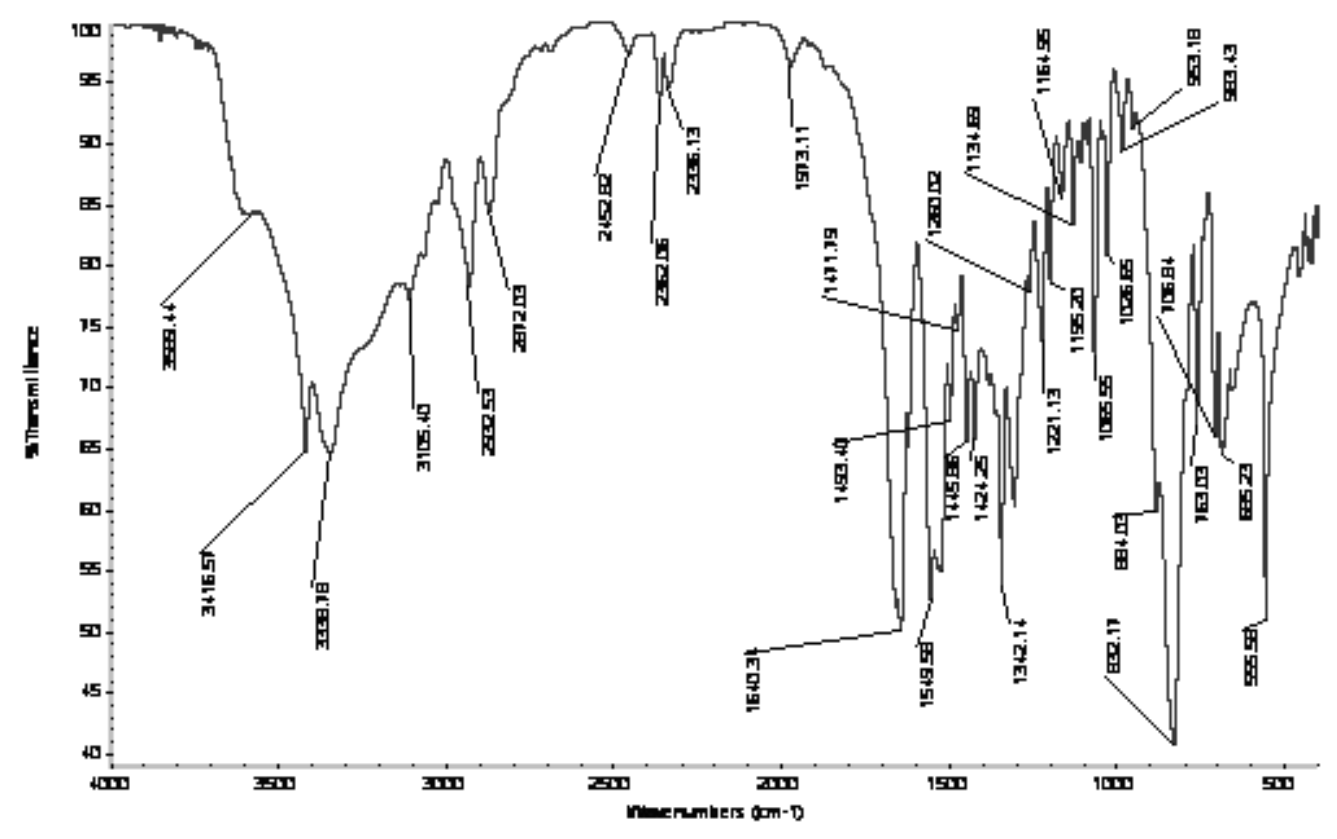


IR Spectrum of 12:

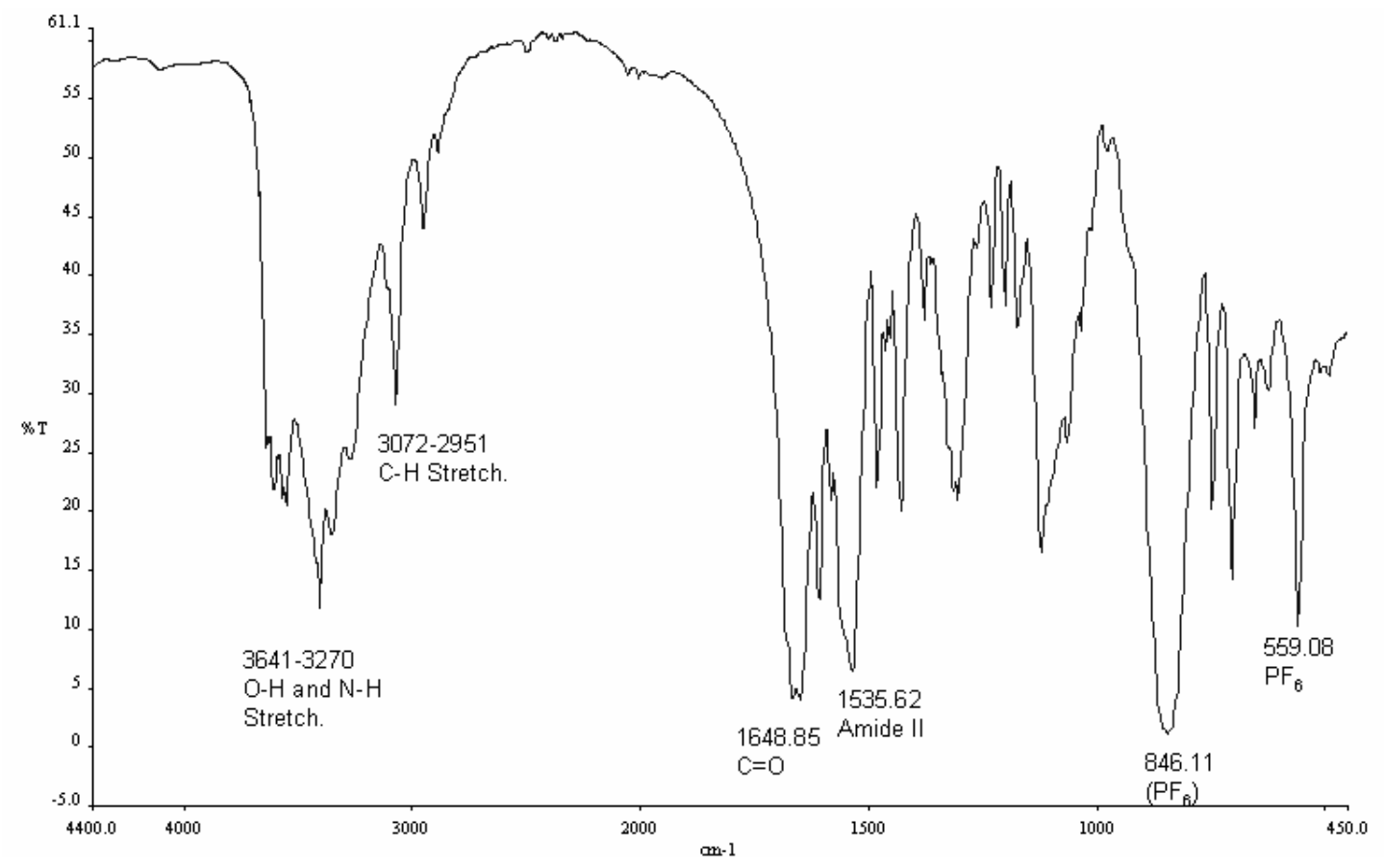

\section{IR Spectrum of 13:}

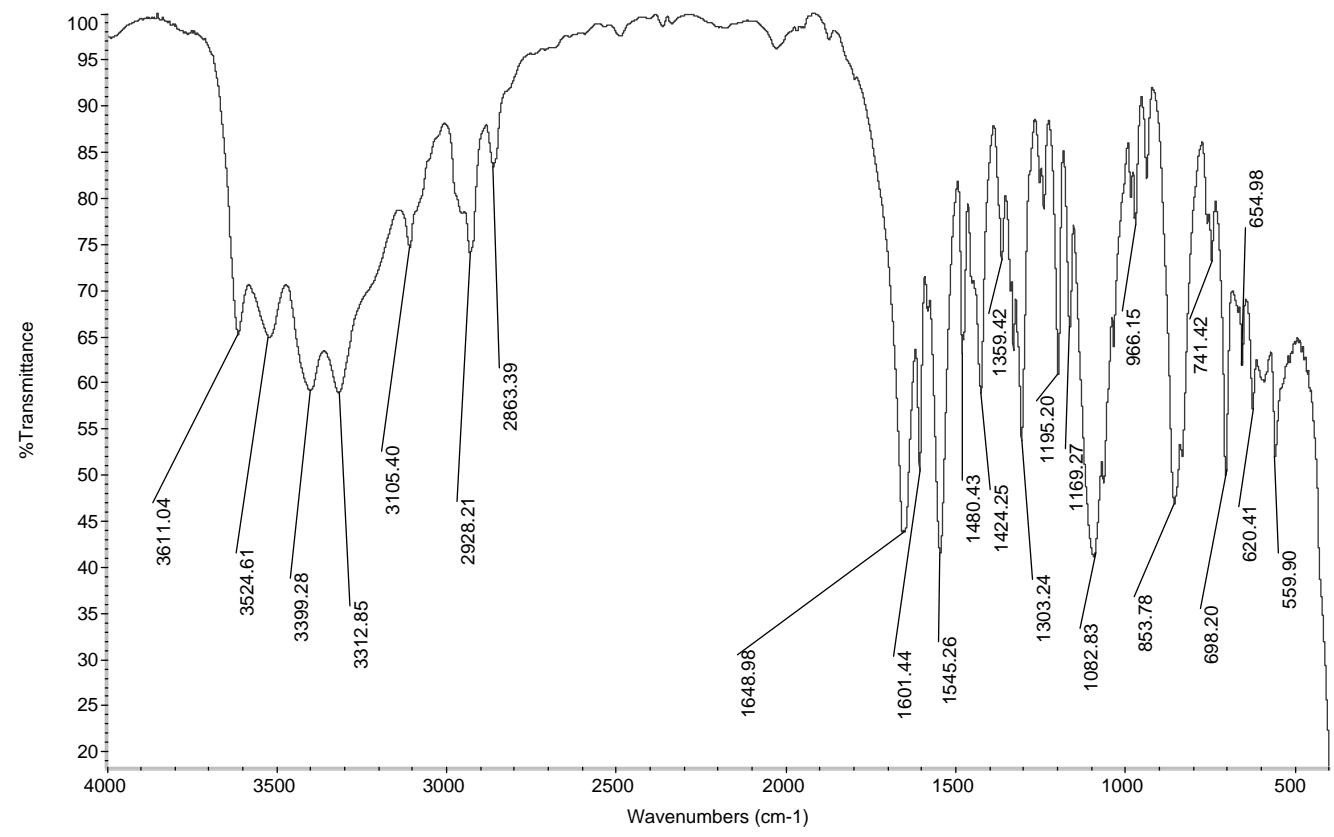


IR spectra of complexes 6, 7, 6 in EtOH and 7 in nitrobenzene:

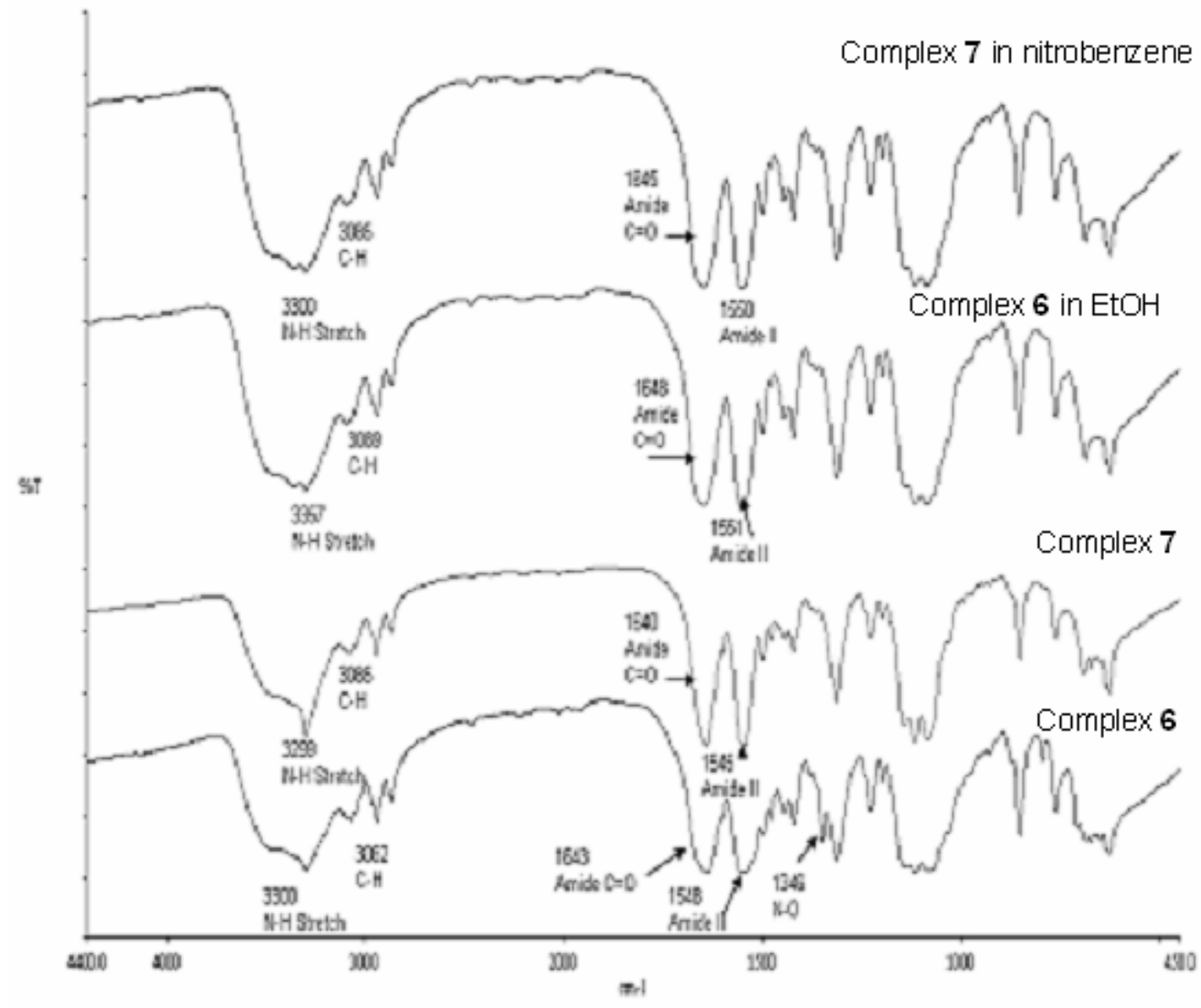


Guest Exchange Reactions of Complex 6:

IR Spectra of complex $\mathbf{6}$ and guest exchange reactions of $\mathbf{6}$ with various aromatic solvents:

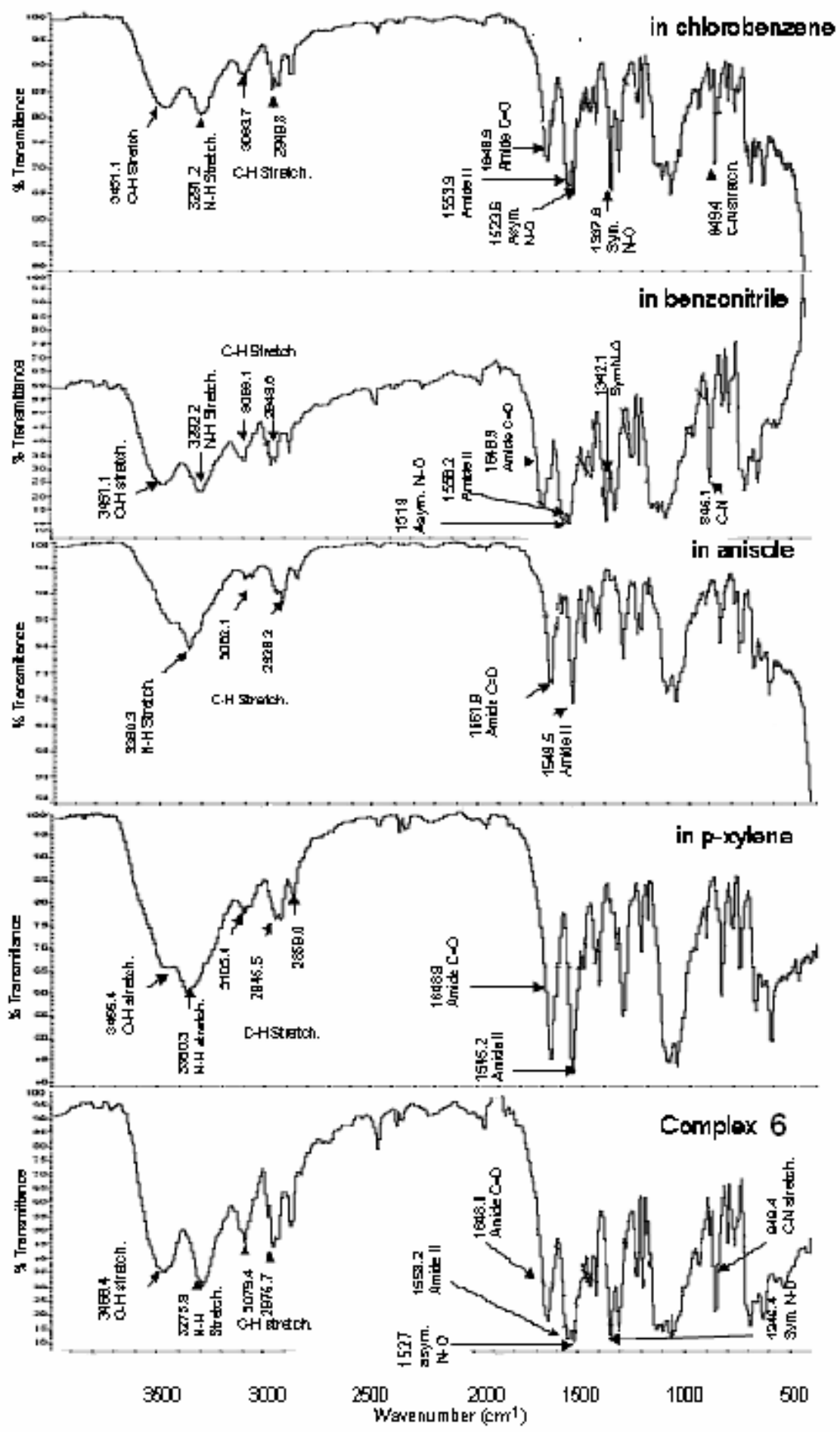


Anion Exchange reaction of 8 with $\mathrm{ClO}_{4}$ :

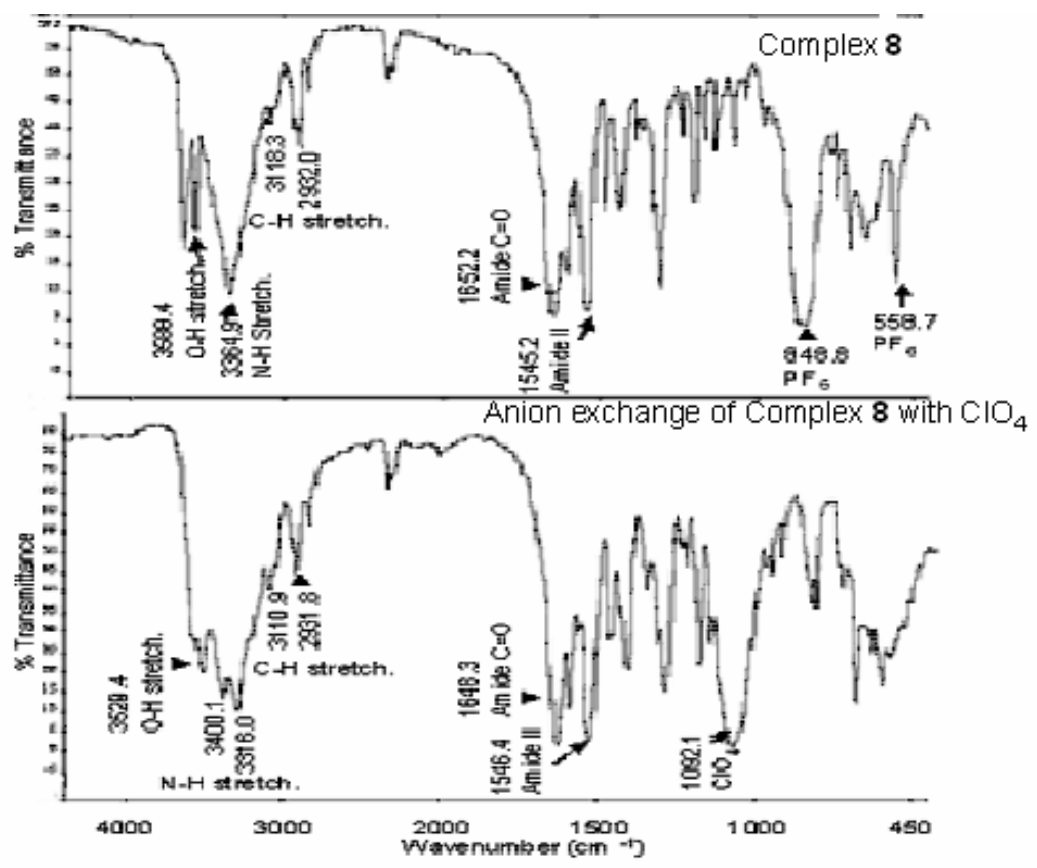

IR of complex 9; complex 13 and anion exchange of 13:

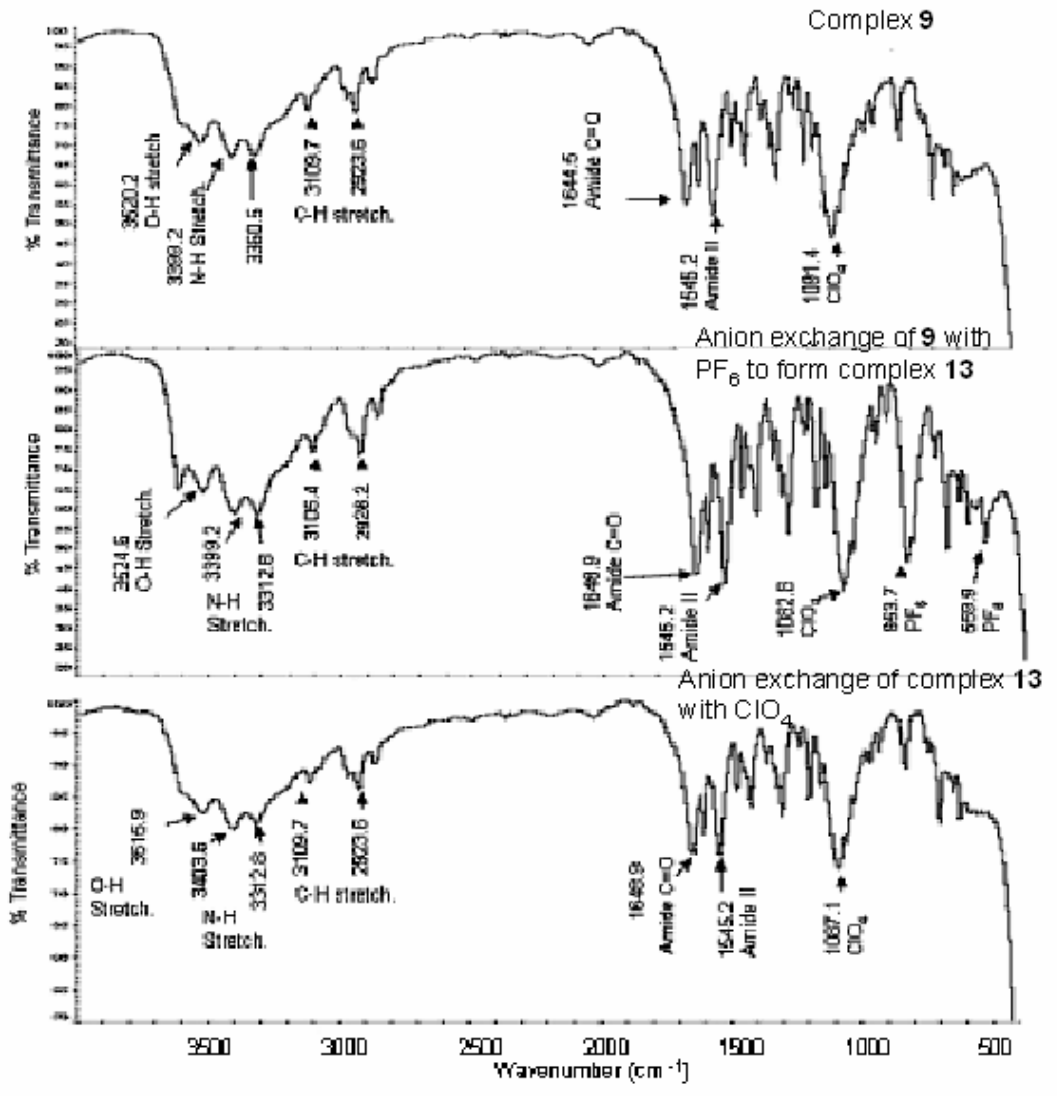


Thermal Gravimetric Analyses of 4, 6, 7 and 9:

TGA of 4a:

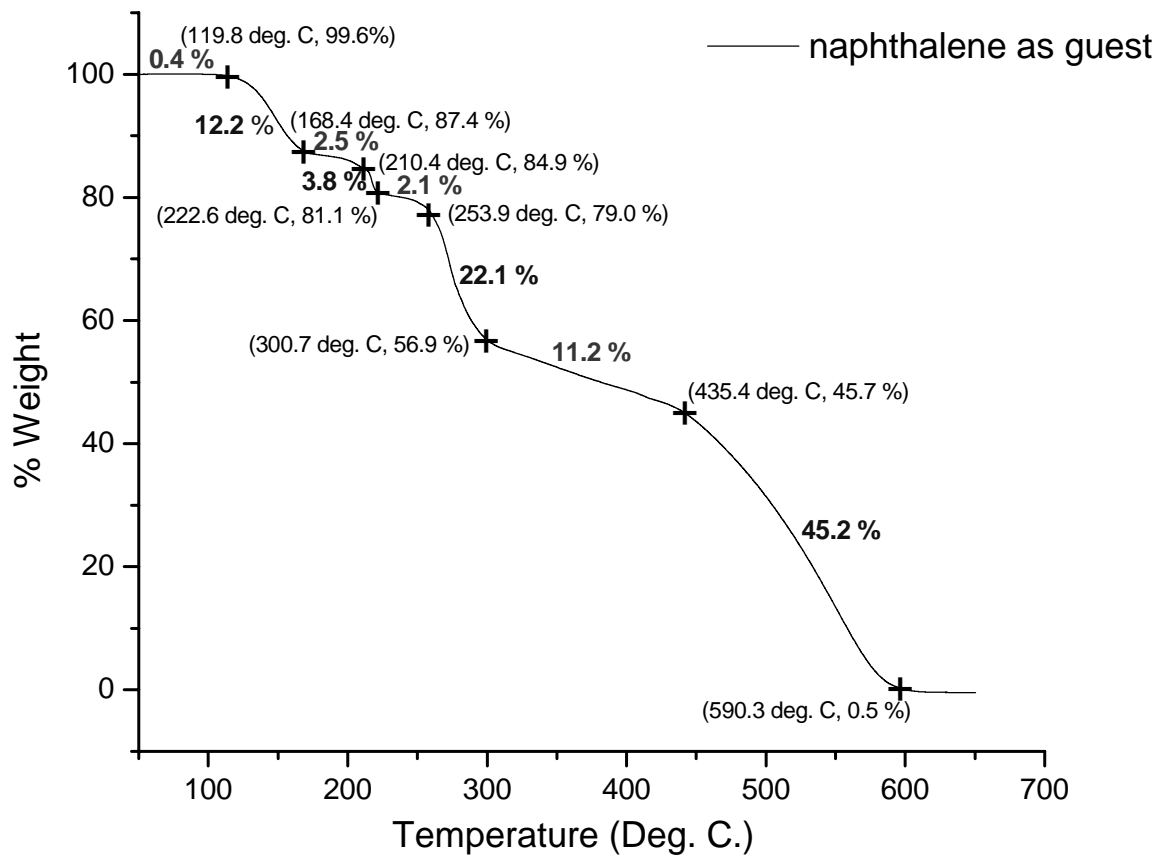

TGA of $\mathbf{4 b}$ :

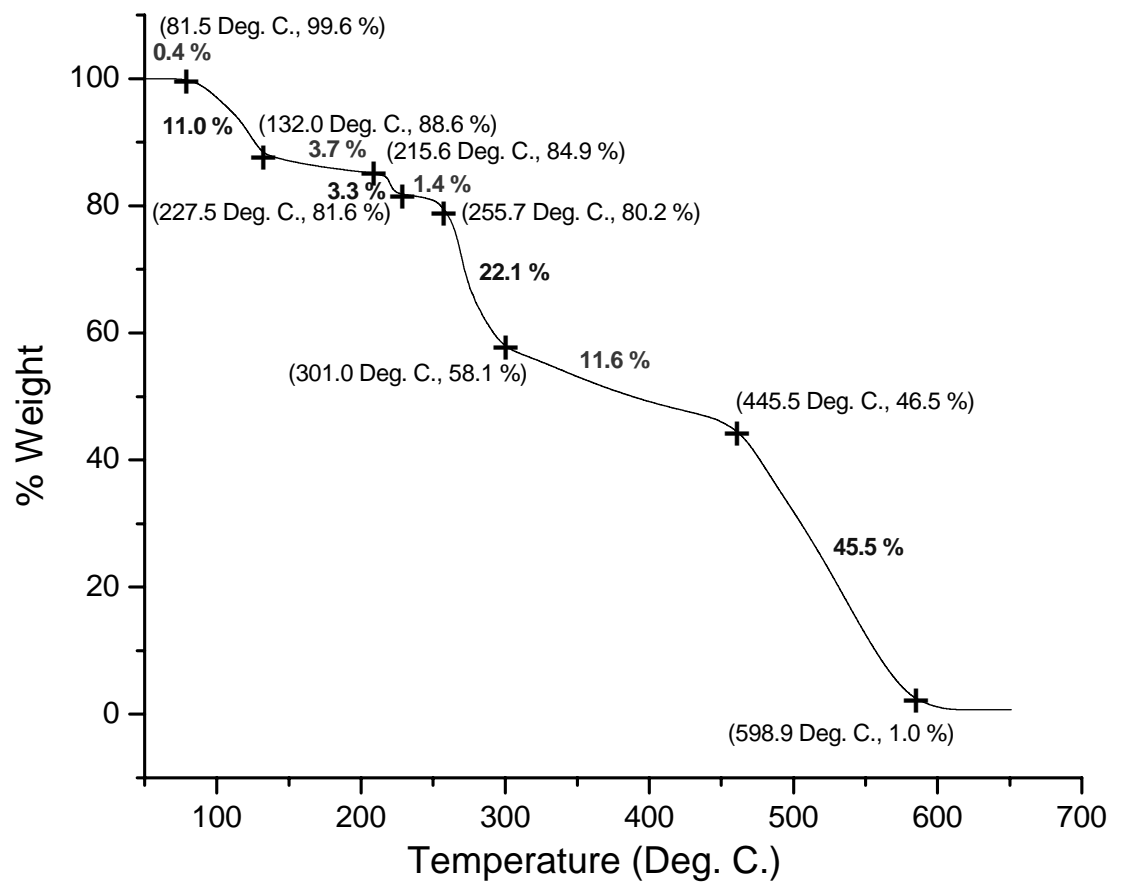


TGA of 4c:

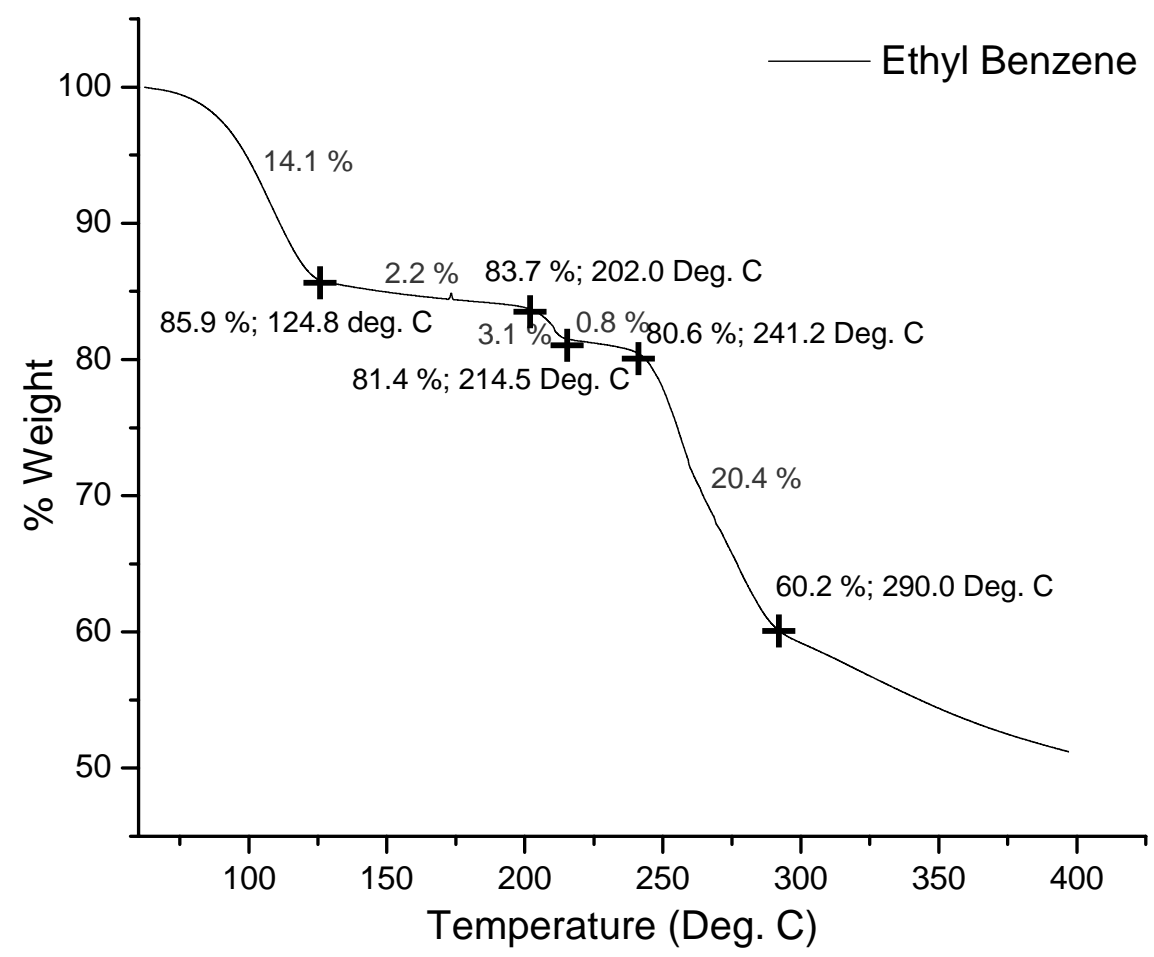

TGA of 4d:

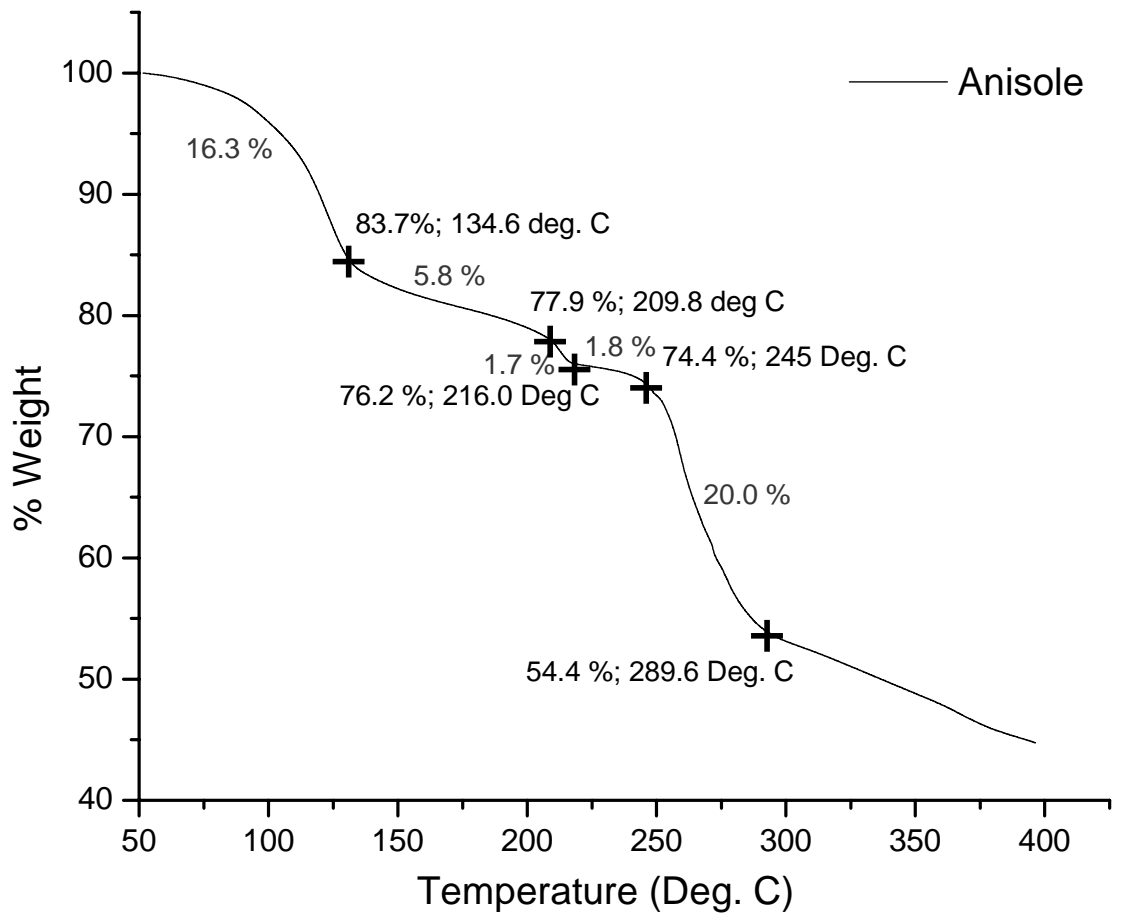


TGA of $\mathbf{6}$ :

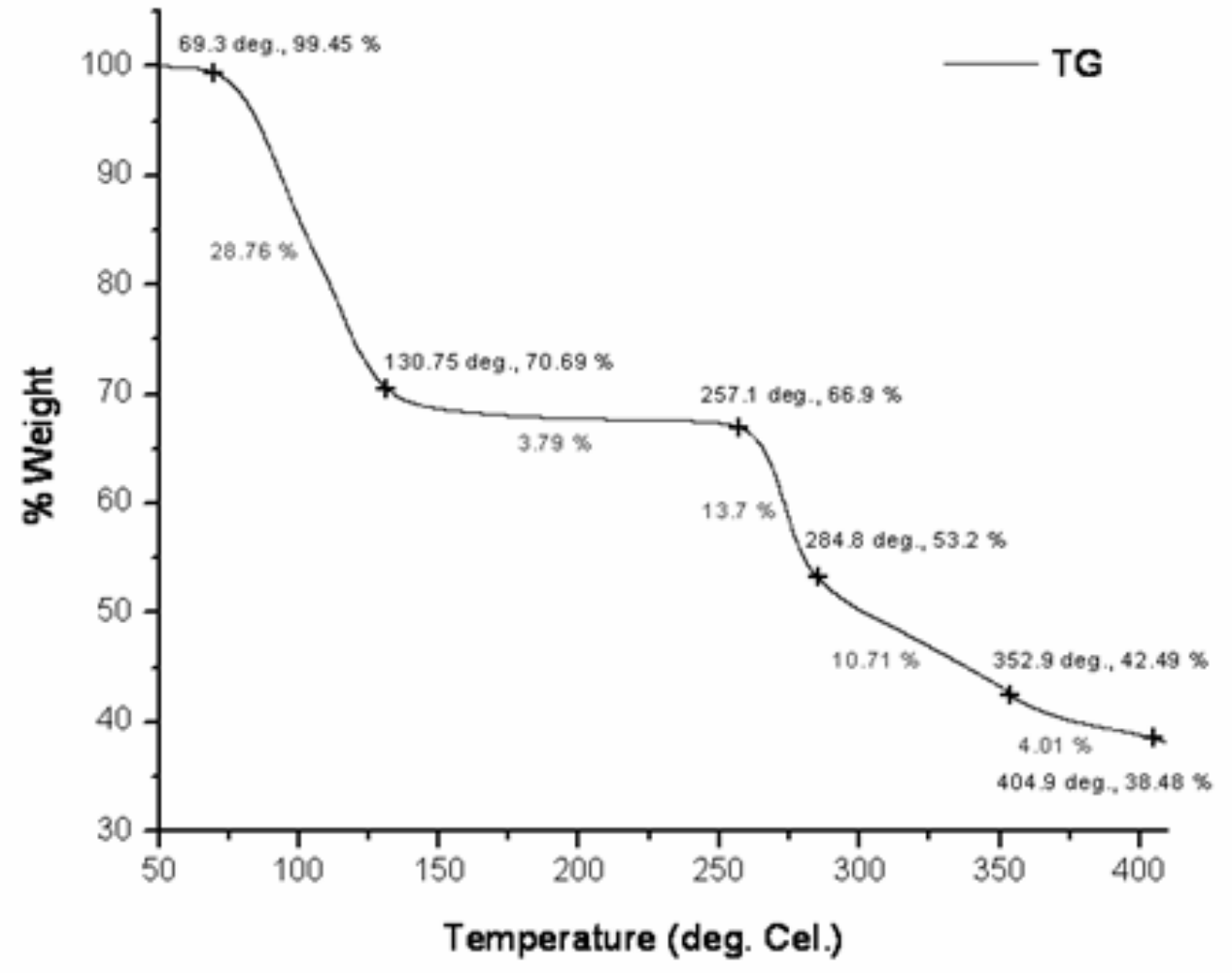

TGA of 7:

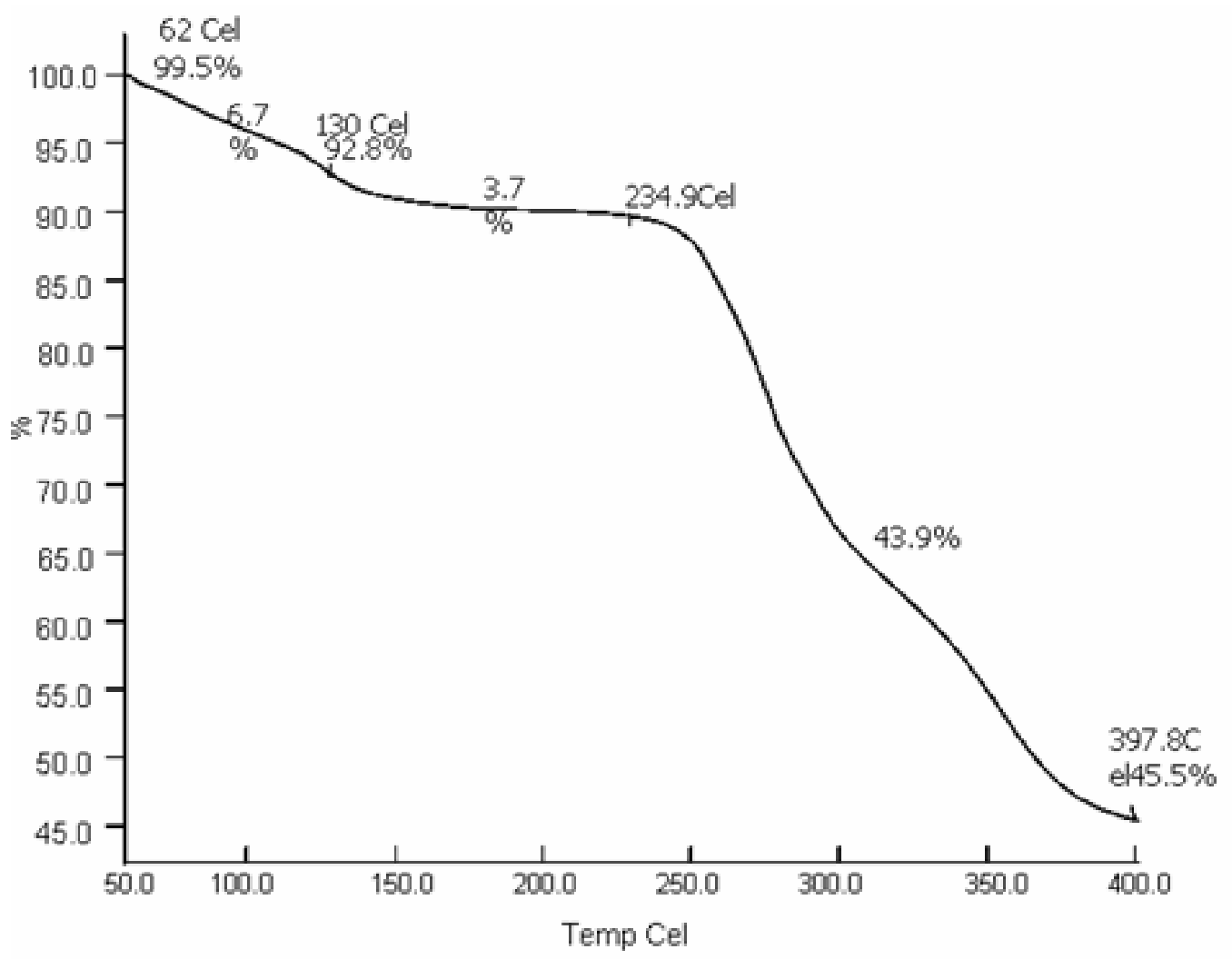


TGA of 9:

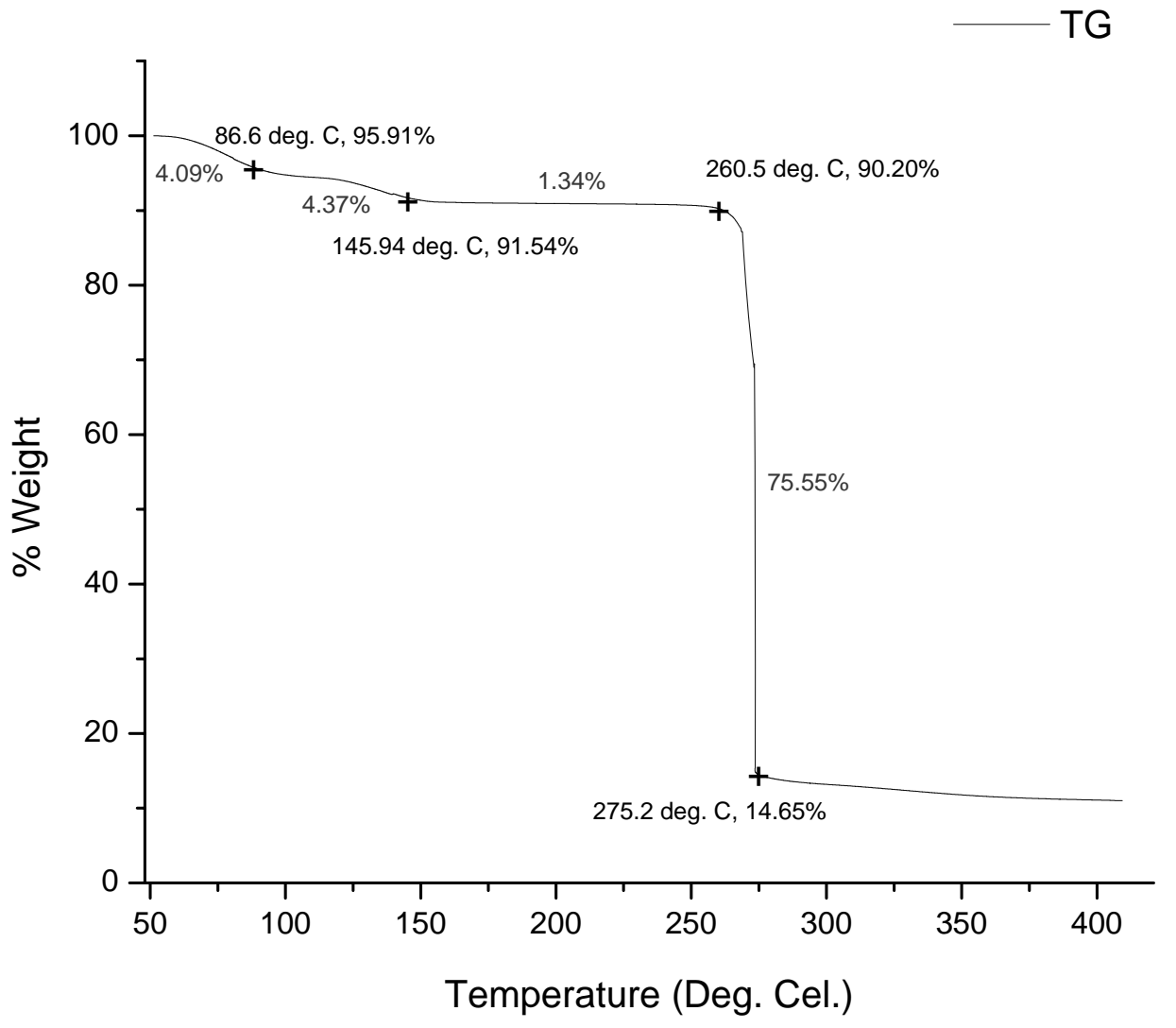

Powder XRD Pattern of Guest Exchange Reactions of Complex 6:

Complex 7

in nitrobenzene

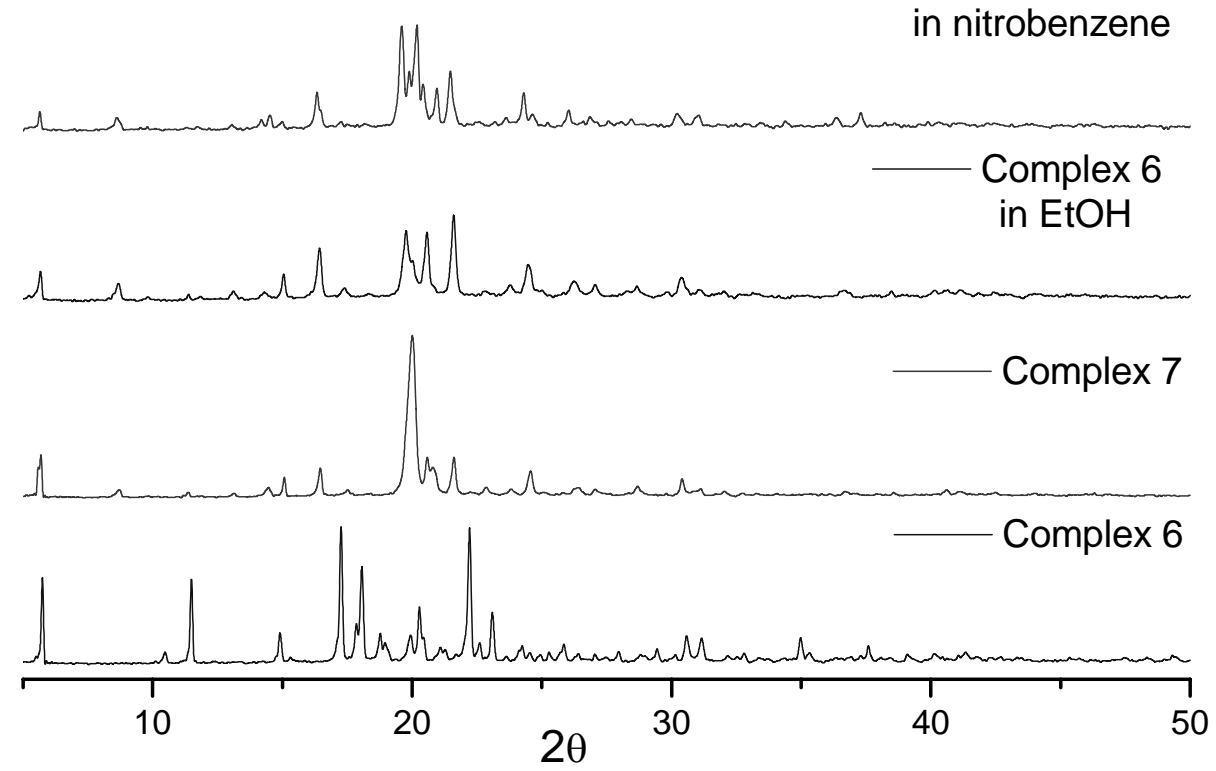


delangand

- Complex 6 in Chlorobenzene

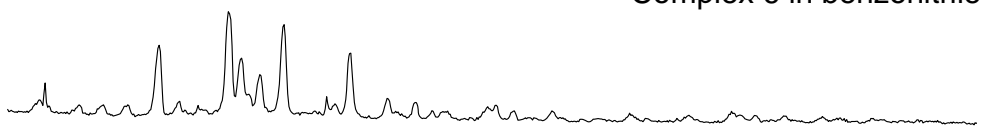

Complex 6 in p-xylene
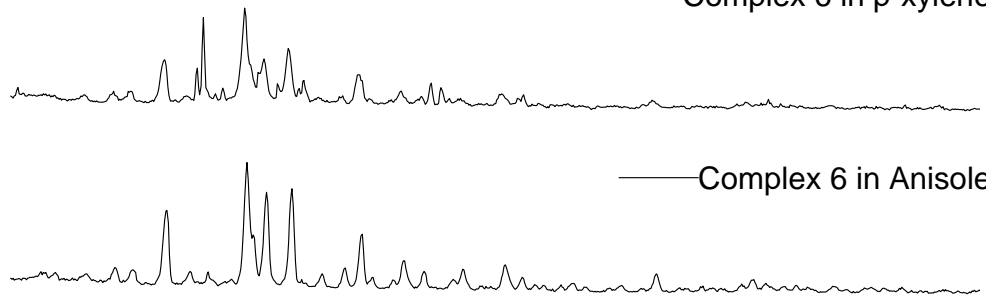

- Complex 6 after removal of nitrobenzene

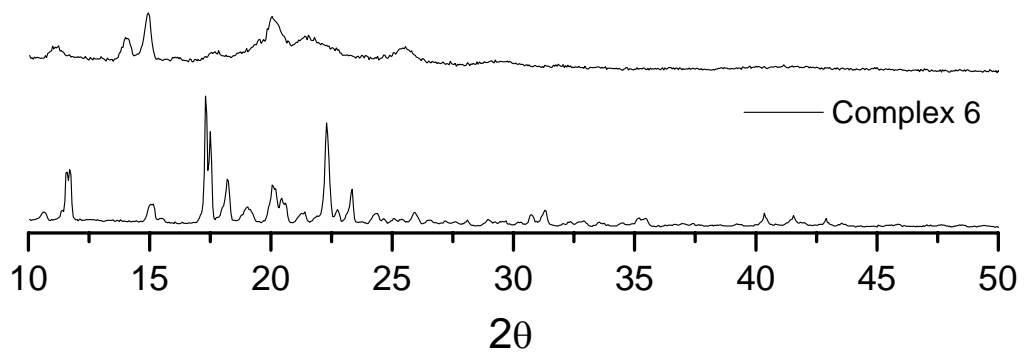

